\title{
Laboratory evaluation of the COBAS MIRA S random access analyser
}

\author{
Taweesook Kanluan, Srisanit Intaramanee, Surapon \\ Tangvorasittichai, Orathai Tangvorasittichai, \\ Lerson Suwanton, Sudarat Manochiopinij, \\ Soontharee Tantrarongroj and Pimpan Leangphibul \\ Department of Clinical Chemistry, Faculty of Medical Technology, Mahidol \\ University, Bangkok 10700, Thailand
}

The random access analyser COBAS MIRA $S$ (Roche Diagnostics) was evaluated for two months. The instrument is a computer-controlled discrete analyser which can be run in a combination profile and/or single test mode. This instrument has special features, including an automatic cuvette segment changer, a reagent rack cooling system, an external keyboard and monitor, as well as a bar-code facility for the entry of test parameters, worklists and sample identification numbers. Study of within-run and between-run precision gave values of $\% C V=0.54-3.37$ and 0.61 $3 \cdot 65$, respectively, for a variety of assays. Linearity testing to the upper limit of each test was also studied and were found to cover the necessary pathological range. Within the two-month period, no major problems were encountered. The instrument required minimum operator attention during operation. Correlation studies with the Hitachi 705 using six clinical chemistry tests (glucose, cholesterol, triglyceride, ALP, AST, ALT) gave correlation coefficients ranging from 0.95-0.99 and slopes of 0.91-1.17.

\section{Introduction}

In recent years, random access analysers have attracted considerable interest among clinical chemists in small- to medium-sized laboratories because of their obvious advantages with regard to flexibility, immediate readiness and reliability [1,2]. The random access analyser COBAS MIRA $\mathrm{S}$ is an extended version of the wellknown COBAS MIRA [3]. This (MIRA S) analyser has an automatic cuvette segment changer, a cooled reagent compartment and improved system software. The filterphotometer system can be monitored in parallel at five different wavelengths: $340,405,500,550$ and $600 \mathrm{~nm}$. The working temperature $30^{\circ} \mathrm{C}$ is sustained by an air bath and monitored by a thermistor located within the chamber. The software permits the determination of routine clinical chemical analytes by using theoretical calculation factors, calibrators or standard dilution curves. Predilutions of standards and/or samples can be programmed easily. The test results of the determinations are automatically transferred to the 'patient report'. Each patient's data can be recalled and printed whenever needed.

In this paper, the results of an assessment on the analytical performance of COBAS MIRA S are reported. Six routine chemistry tests were selected (table 1) for use in the study of its suitability and usefulness in small- to medium-sized laboratories where routine service and stat tests in both batch and random access mode are performed. The evaluation studies performed included within-run and between-run precision at four analyte concentrations, method linearity and relative accuracy (comparison studies).

Table 1. Methods and volumes used on the COBAS MIRA S.

\begin{tabular}{llcc}
\hline Test & \multicolumn{1}{c}{ Method basis } & $\begin{array}{c}\text { Sample } \\
\text { vol. } \\
(\mu \mathrm{l})\end{array}$ & $\begin{array}{c}\text { Total } \\
\text { reagent } \\
\text { vol. } \\
(\mu \mathrm{l})\end{array}$ \\
\hline Glucose & $\begin{array}{c}\text { UNI-KIT: Hexokinase } \\
\text { (UV endpoint) }\end{array}$ & $4 \cdot 0$ & 200 \\
Cholesterol & $\begin{array}{c}\text { UNI-KIT: Cholesterol oxi- } \\
\text { dase (PAP) }\end{array}$ & $4 \cdot 0$ & 350 \\
Triglyceride & $\begin{array}{c}\text { UNI-KIT: Colorimetric } \\
\text { end-point (PAP) }\end{array}$ & $4 \cdot 0$ & 300 \\
ALP & $\begin{array}{c}\text { UNI-KIT: Kinetic at } \\
405 \text { nm (IFCC, } 37^{\circ} \mathrm{C} \text { ) }\end{array}$ & $6 \cdot 0$ & 250 \\
AST & $\begin{array}{c}\text { UNI-KIT: Kinetic at } \\
340 \text { nm (IFCC, } 37^{\circ} \mathrm{C} \text { ) }\end{array}$ & $16 \cdot 0$ & 145 \\
ALT & $\begin{array}{c}\text { UNI-KIT: Kinetic at } \\
340 \text { nm (IFCC, } 37^{\circ} \mathrm{C} \text { ) }\end{array}$ & $16 \cdot 0$ & 145 \\
\hline
\end{tabular}

\section{Materials and methods}

Instruments

The COBAS MIRA $S$ was on loan from Roche Diagnostics, Switzerland. All necessary reagents (UNIKIT) and calibrators were also supplied by Roche. The methods employed for the six analytes, the amount of sample volumes and total reagent volumes are shown in

Table 2. Methods and volumes for comparison used on the Hitachi 705 .

\begin{tabular}{|c|c|c|c|}
\hline Test & Method basis & $\begin{array}{c}\text { Sample } \\
\text { vol. } \\
(\mu \mathrm{l})\end{array}$ & $\begin{array}{c}\text { Total } \\
\text { reagent* } \\
\text { vol. } \\
(\mu \mathrm{l})\end{array}$ \\
\hline Glucose & Glucose oxidase (PAP) & $5 \cdot 0$ & 500 \\
\hline Cholesterol & Cholesterol oxidase (PAP) & $4 \cdot 0$ & 350 \\
\hline Triglyceride & $\begin{array}{l}\text { Colorimetric end-point } \\
\text { (PAP) }\end{array}$ & $4 \cdot 0$ & 350 \\
\hline ALP & $\begin{array}{l}\text { Kinetic at } 405 \mathrm{~nm} \text { (IFCC, } \\
37^{\circ} \mathrm{C} \text { ) }\end{array}$ & $5 \cdot 0$ & 350 \\
\hline AST & $\begin{array}{l}\text { Kinetic at } 340 \mathrm{~nm} \text { (IFCC, } \\
37^{\circ} \mathrm{C} \text { ) }\end{array}$ & $20 \cdot 0$ & 385 \\
\hline ALT & $\begin{array}{l}\text { Kinetic at } 340 \mathrm{~nm} \text { (IFCC, } \\
37^{\circ} \mathrm{C} \text { ) }\end{array}$ & $20 \cdot 0$ & 385 \\
\hline
\end{tabular}

* All reagents were supplied by Roche Diagnostics. 
T. Kanluan et al. Laboratory evaluation of the COBAS MIRA S random access analyser

Table 3. Within-run precision at four analyte concentrations. Coefficients of variation (CV) are given in $\%(N=20)$.

\begin{tabular}{|c|c|c|c|c|c|c|c|c|c|c|c|c|}
\hline \multirow[b]{2}{*}{ Sample } & \multicolumn{2}{|c|}{$\begin{array}{l}\text { Glucose } \\
(\mathrm{mmol} / \mathrm{l})\end{array}$} & \multicolumn{2}{|c|}{$\begin{array}{l}\text { Cholesterol } \\
(\mathrm{mmol} / \mathrm{l})\end{array}$} & \multicolumn{2}{|c|}{$\begin{array}{l}\text { Triglyceride } \\
(\mathrm{mmol} / \mathrm{l})\end{array}$} & \multicolumn{2}{|c|}{$\operatorname{ALP}(\mathrm{I} . \mathrm{U} . / \mathrm{l})$} & \multicolumn{2}{|c|}{ AST (I.U./l) } & \multicolumn{2}{|c|}{$\operatorname{ALT}(\mathrm{I} . \mathrm{U} . / \mathrm{l})$} \\
\hline & Mean & $\mathrm{CV}$ & Mean & $\mathrm{CV}$ & Mean & CV & Mean & $\mathrm{CV}$ & Mean & CV & Mean & $\mathrm{CV}$ \\
\hline Control N* & $5 \cdot 58$ & $1 \cdot 47$ & 1.96 & $1 \cdot 68$ & $0 \cdot 29$ & $1 \cdot 81$ & $63 \cdot 08$ & $1 \cdot 48$ & $150 \cdot 10$ & 0.63 & $39 \cdot 11$ & 0.97 \\
\hline Control P & $11 \cdot 96$ & $1 \cdot 58$ & $1 \cdot 81$ & $1 \cdot 04$ & $0 \cdot 37$ & $2 \cdot 11$ & $191 \cdot 80$ & $0 \cdot 89$ & $189 \cdot 30$ & $0 \cdot 54$ & $91 \cdot 53$ & $0 \cdot 72$ \\
\hline Giba-Corning & $4 \cdot 31$ & $1 \cdot 30$ & $3 \cdot 34$ & 0.75 & $0 \cdot 96$ & $1 \cdot 53$ & $72 \cdot 74$ & $1 \cdot 65$ & $26 \cdot 47$ & $2 \cdot 81$ & $23 \cdot 19$ & $2 \cdot 36$ \\
\hline Lyophil & $4 \cdot 66$ & $0 \cdot 70$ & $3 \cdot 73$ & 0.99 & $1 \cdot 34$ & $1 \cdot 20$ & $67 \cdot 43$ & $0 \cdot 76$ & $45 \cdot 13$ & $0 \cdot 81$ & $21 \cdot 67$ & 3.67 \\
\hline
\end{tabular}

* Lot K 1736.

Table 4. Between-run precision at four analyte concentrations. Coefficients of variation $(C V)$ are given in $\%(N=20)$.

\begin{tabular}{|c|c|c|c|c|c|c|c|c|c|c|c|c|}
\hline \multirow[b]{2}{*}{ Sample } & \multicolumn{2}{|c|}{$\begin{array}{l}\text { Glucose } \\
(\mathrm{mmol} / \mathrm{l})\end{array}$} & \multicolumn{2}{|c|}{$\begin{array}{l}\text { Cholesterol } \\
(\mathrm{mmol} / \mathrm{l})\end{array}$} & \multicolumn{2}{|c|}{$\begin{array}{l}\text { Triglyceride } \\
(\mathrm{mmol} / \mathrm{l})\end{array}$} & \multicolumn{2}{|c|}{ ALP (I.U./l) } & \multicolumn{2}{|c|}{ AST (I.U./l) } & \multicolumn{2}{|c|}{$\operatorname{ALT}($ I.U./l) } \\
\hline & Mean & CV & Mean & CV & Mean & CV & Mean & $\mathrm{CV}$ & Mean & GV & Mean & $\mathrm{CV}$ \\
\hline Control N* & $5 \cdot 08$ & $1 \cdot 00$ & $1 \cdot 70$ & $1 \cdot 33$ & $0 \cdot 27$ & $3 \cdot 17$ & $64 \cdot 85$ & $3 \cdot 65$ & $134 \cdot 55$ & $0 \cdot 61$ & $33 \cdot 00$ & $0 \cdot 98$ \\
\hline Control P & $12 \cdot 68$ & 1.44 & $1 \cdot 81$ & 1.93 & $0 \cdot 39$ & $3 \cdot 15$ & $211 \cdot 55$ & $1 \cdot 48$ & $194 \cdot 30$ & $1 \cdot 11$ & $90 \cdot 85$ & $1 \cdot 02$ \\
\hline Ciba-Corning-N & $4 \cdot 80$ & $1 \cdot 33$ & $3 \cdot 49$ & $1 \cdot 74$ & 0.94 & $1 \cdot 86$ & $84 \cdot 25$ & $3 \cdot 51$ & $27 \cdot 20$ & $2 \cdot 82$ & $24 \cdot 90$ & $2 \cdot 81$ \\
\hline Lyophil & $5 \cdot 08$ & $0 \cdot 62$ & $3 \cdot 89$ & $1 \cdot 22$ & $1 \cdot 36$ & $1 \cdot 21$ & $78 \cdot 10$ & $2 \cdot 78$ & $46 \cdot 25$ & $1 \cdot 38$ & $24 \cdot 90$ & $3 \cdot 17$ \\
\hline
\end{tabular}

* Lot K 1440.

Table 5. Linearity of assays as performed by the COBAS MIRA S.

\begin{tabular}{ll}
\hline Test & \multicolumn{1}{c}{$\begin{array}{c}\text { Determined range } \\
\text { of linearity }\end{array}$} \\
\hline Glucose & $0 \cdot 56-26 \cdot 42 \mathrm{mmol} / \mathrm{l}$ \\
Cholesterol & $0-18 \cdot 10 \mathrm{mmol} / \mathrm{l}$ \\
Triglyceride & $0-6 \cdot 58 \mathrm{mmol} / 1$ \\
ALP & $0-975 \mathrm{I} . \mathrm{U} . / \mathrm{l}$ \\
AST & $0-397$ I.U./1 \\
ALT & $0-428$ I.U./l \\
\hline
\end{tabular}

Table 6. Linear regression statistics for the COBAS MIRA $S$ (yaxis) against the Hitachi 705 (x-axis).

\begin{tabular}{lcccc}
\hline Test & Slope & y-intercept & $\begin{array}{c}\text { Correlation } \\
\text { coefficient }\end{array}$ & $N$ \\
\hline Glucose & 0.91 & 14.18 & 0.98 & 126 \\
Cholesterol & 0.98 & -11.76 & 0.99 & 127 \\
Triglyceride & 1.00 & -0.79 & 0.99 & 147 \\
ALP & 1.17 & -2.36 & 0.99 & 120 \\
AST & 1.04 & 1.44 & 0.99 & 121 \\
ALT & 1.01 & 0.27 & 0.99 & 124 \\
\hline
\end{tabular}

table 1. All reagents were prepared according to the manufacturer's instructions. The analyser used in the comparison study was the Hitachi 705 (Boehringer Mannheim, Germany), this was the instrument used by the laboratory before the arrival of the COBAS MIRA S. All methods used on the Hitachi 705 were performed and calibrated with Roche Diagnostics reagents, calibrators and controls. Methods, sample volumes and total reagent volumes are shown in table 2 .

\section{Specimens}

The following commercially available control sera were used in the precision studies according to the manufacturer's instructions: (1) control serum N: lot K 1736 and lot K 1440 and control serum P: lot C 2741 Roche Diagnostics; (2) Ciba-Corning: lot Ch-B: 036701, USA and (3) Lyophil: lot 0186005 (locally produced, distributed by the faculty of Medical Technology, Mahidol University).

More than 120 patient samples (low, normal and abovenormal levels) were selected for comparison studies. Half of each specimen was used for assays in the COBAS MIRA S, while the other half was used for assays in the Hitachi 705. The above-normal concentration specimens were used in the linearity studies.

\section{Calibration}

The COBAS MIRA S and the Hitachi 705 were calibrated with Roche Diagnostics calibration material.

\section{Results}

\section{Precision}

The evaluation of the performance of COBAS MIRA S took two months. Close supervision and appropriate training were given initially by Roche Diagnostics (Thailand) Ltd. Within-run and between-run precisions were assessed. Six clinical chemical analytes were selected; glucose, cholesterol, triglyceride, alkaline phosphatese (ALP), aspartate aminotransferase (AST) and alanine aminotransferase (ALT). For within-run studies, four commercially available control sera were analysed 20 times each in single batches, while the between-run 
T. Kanluan et al. Laboratory evaluation of the COBAS MIRA S random access analyser
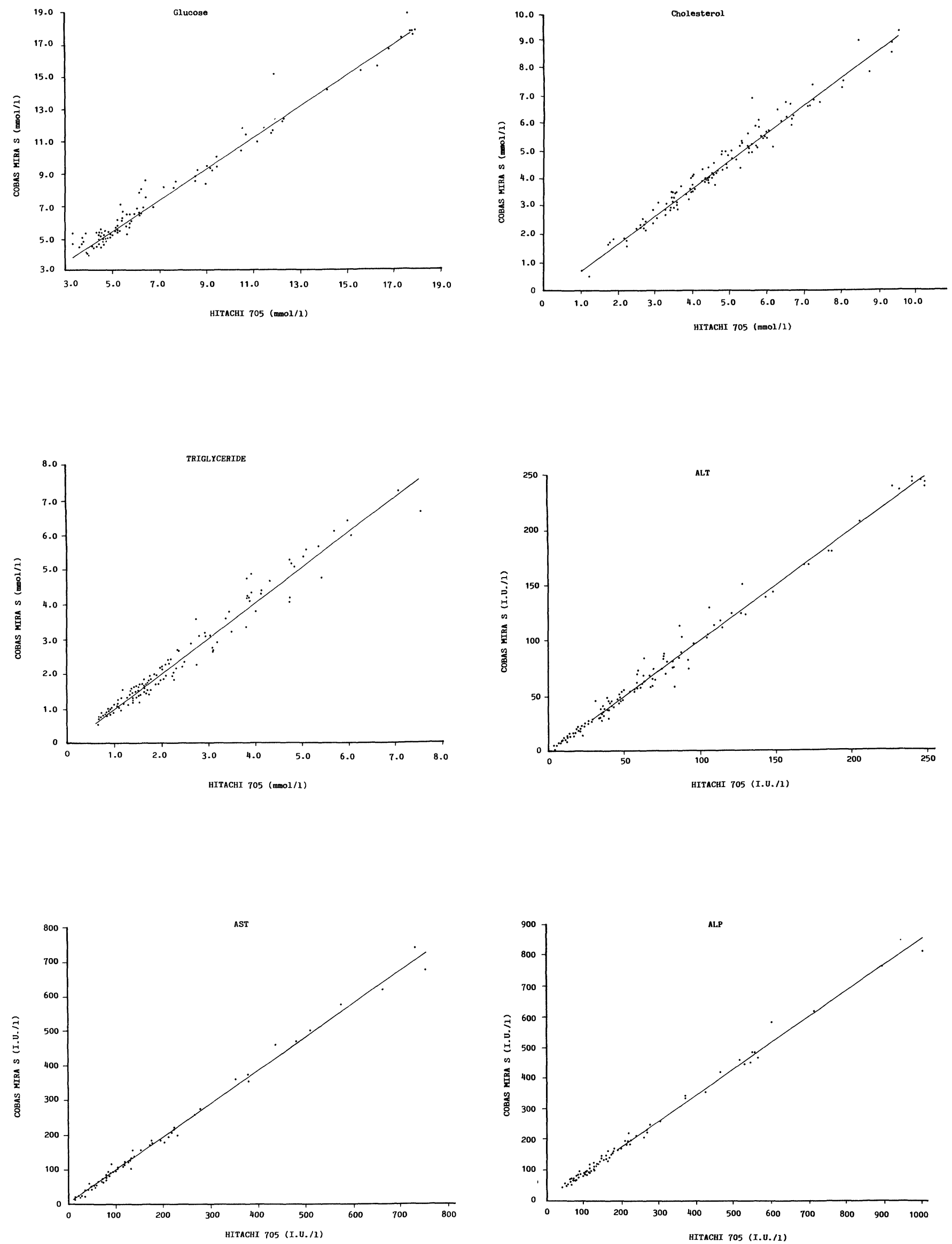

Figure 1. Comparison of results for the six analytes determined on the COBAS MIRAS (y-axis) and the Hitachi 705 (x-axis). Refer to tables 1 and 2 for the details of the methods used in the analysis. 
precision was estimated by running the same sera on 20 separate days. The values of the imprecision within-run and between-run obtained are shown in tables 3 and 4 , respectively. The overall \% $\mathrm{CV}$ of both precision studies gave values of not greater than $3 \%$.

\section{Linearity}

High value samples that greatly exceed the upper limit of determinations were appropriately diluted with isotonic saline for use in linearity studies of each method. The upper limit of each analyte obtained from the study is shown in table 5 . The upper limits were in close agreement with the expected range for each analyte as claimed by the manufacturer.

\section{Accuracy}

More than 120 serum samples, representing both normal and abnormal levels were divided and run simultaneously in the COBAS MIRA S and the Hitachi 705. The comparison data which comprise slopes, intercepts and correlation coefficients are shown in table 6 and figure 1. The Hitachi 705 is the independent variable and COBAS MIRA $\mathrm{S}$ is the dependent variable. Good agreement was found in all cases.

\section{Discussion}

The purpose of this study was to assess the overall performance of the COBAS MIRA $\mathrm{S}$ in a clinical laboratory performing routine tests.

The precision data in table 3 and 4 show that the range of precision determined from COBAS MIRA $\mathrm{S}$ is within the acceptable limits. The good precision with $\% \mathrm{CV}$, in the range of $0 \cdot 5-3 \cdot 6$, may be due to the pipetting system, where the reagent and sample probe are washed, and to the individual reaction cuvette used in the test measurement.

The comparison of the test results obtained on serum samples with COBAS MIRA S and with the Hitachi 705 shows that the degree of correlation was very good $(r$ ranging from 0.95-0.99).

In laboratories where ambient controlled temperature is often in the range of $25-30^{\circ} \mathrm{C}$, the rack cooling device is a very useful compartment to hold temperature-sensitive reagents, especially where large batch of reagents are needed to facilitate the 'true walk-away' facility (provided by the manufacturers for 312 analyses to be determined in one run and facilitated by the automatic cuvette segment changer).

The instrument performed well over the evaluation period. No major problems with regards to instrument failure occurred during the study. The operator's manual and guidelines for trouble-shooting were easy to follow.

In conclusion, the COBAS MIRA $\mathrm{S}$ is a flexible, convenient and easy-to-use analyser for either batch or random access work. Its design and operational simplicity provides reliable analytical data, as demonstrated by good correlation with the existing instrument. Unique, cooled reagent reservoirs and sealed serum cups make the COBAS MIRA S an ideal instrument for use in small to medium-sized laboratories where efficient output of laboratory data is required.

\section{Acknowledgement}

The authors wish to express their sincere thanks to Roche Diagnostics (Thailand) for the reagents and technical support.

\section{References}

1. Bonini, P., Ceriotti, F. and Franzini, C., Journal of Automatic Chemistry, 10 (1988), 167.

2. Beny, D. J. and Price, C. P., Journal of Automatic Chemistry, 11 (1989), 15.

3. Lifshity, M. and De Gresce, R., Laboratory Medicine, 17 (1986), 291. 


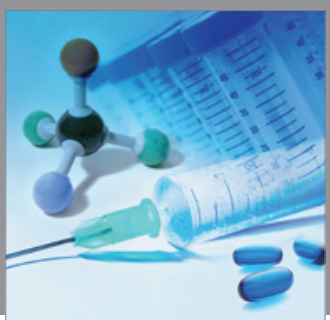

International Journal of

Medicinal Chemistry

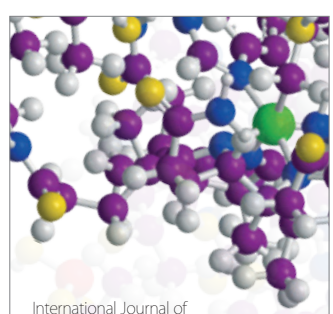

Carbohydrate Chemistry

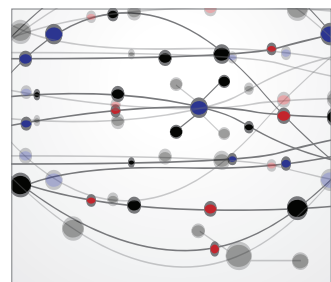

The Scientific World Journal
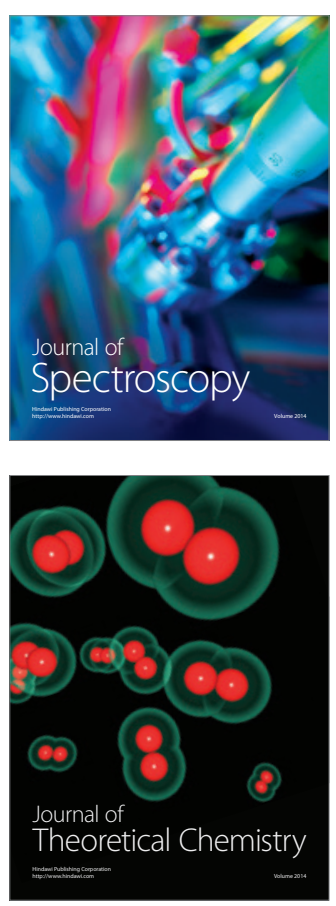
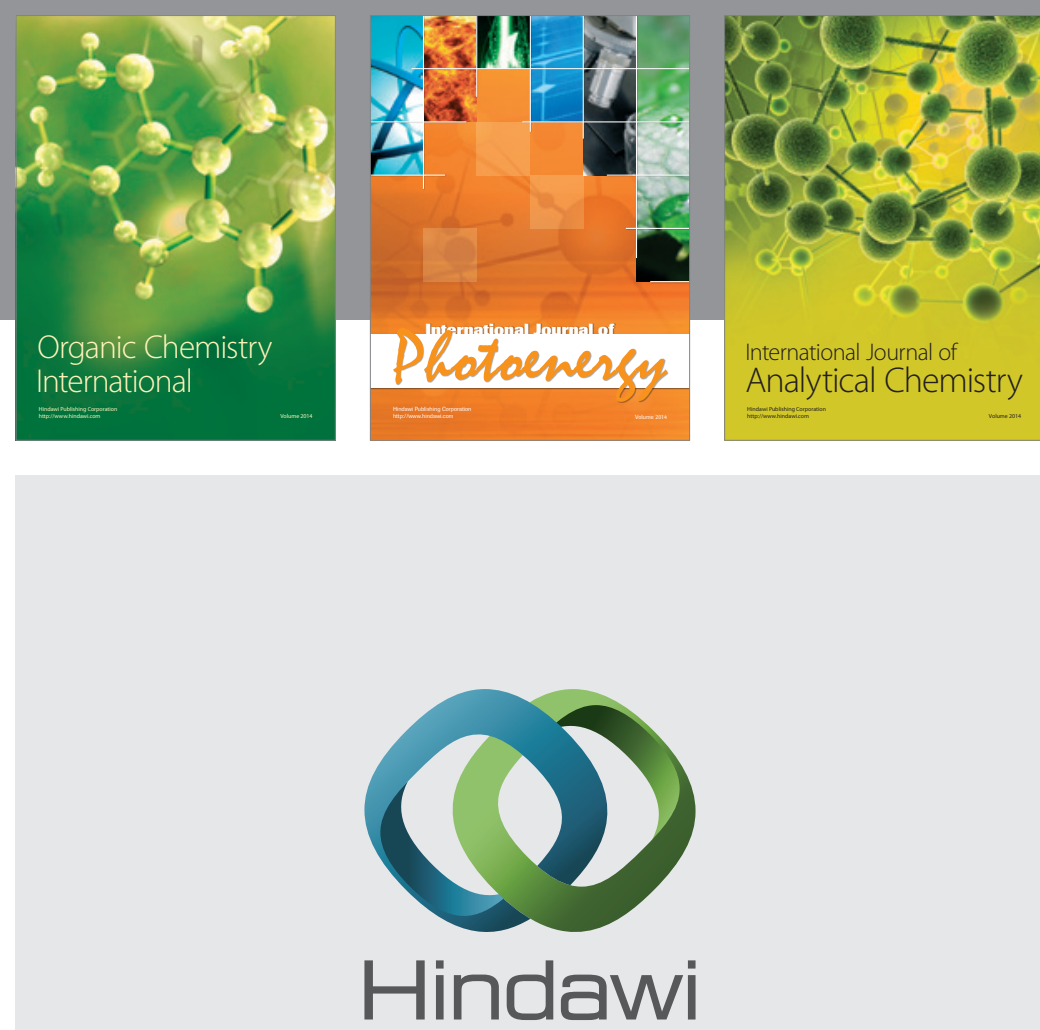

Submit your manuscripts at

http://www.hindawi.com
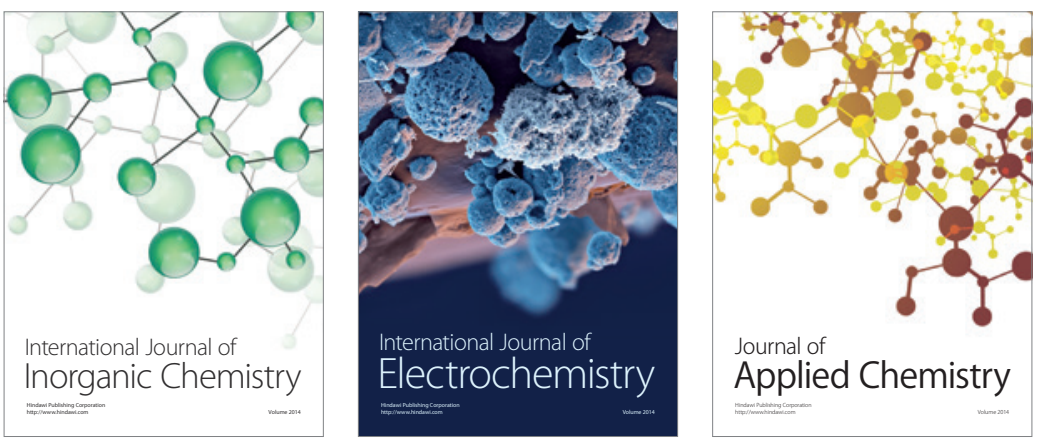

Journal of

Applied Chemistry
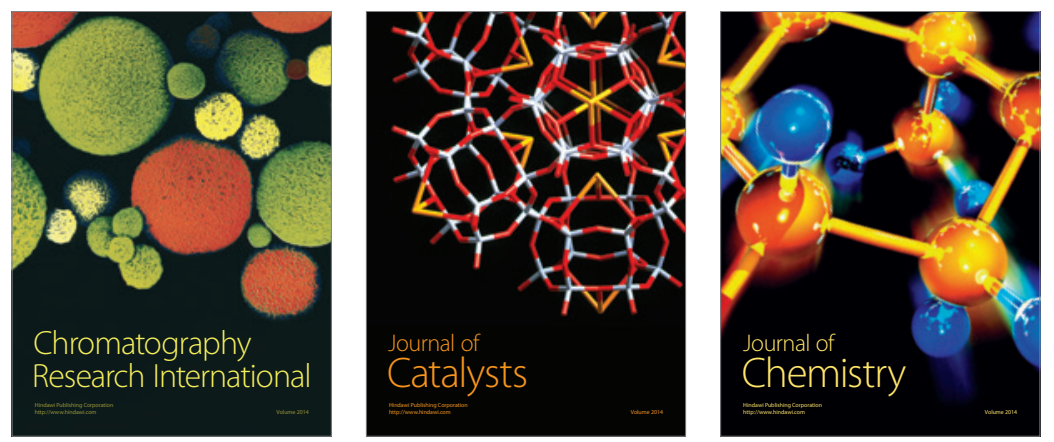
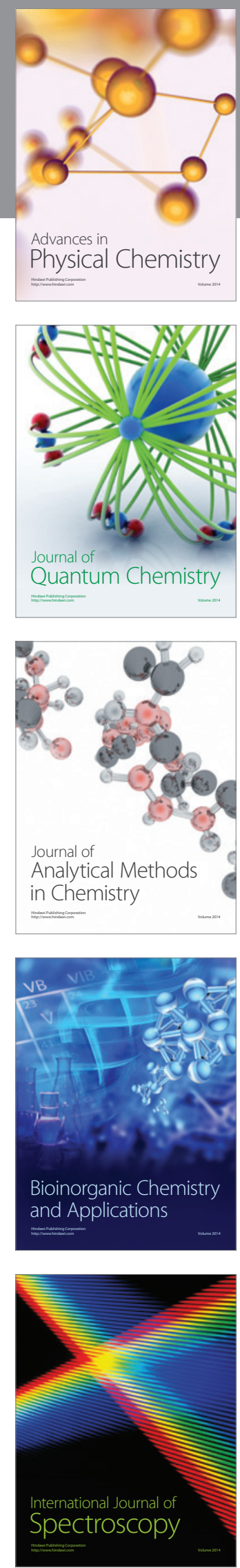